\title{
Evaluation of the clinical examination in thediagnosis of acute medial collateral ligament injury of the knee joint in comparism with examination under general anesthesia
}

\author{
Laith Saleem Sabri F.I.C.M.S. ${ }^{*}$. Ali Ehsan Shafeeq C.A.B.S. ${ }^{*}$, Haider Omran Hayat Ali C.A.B.S*
}

\begin{abstract}
Background: Tear of MCL of the knee is a frequent problem among knee ligaments injuries.Injuries to the MCL are usually caused by contact on the outside of the knee and are accompanied by sharp pain on the inside of the knee. Contrary to most other knee ligaments the medial collateral ligament (MCL) has an excellent ability to heal, being fairly large and well vascularised structure. The vast majority of isolated medial ligament injuries heal without significant long-term problems

Objectives: is to compare between the early clinical examination, and assessment under general anesthesia (GA), and to find out the best methods to assess the MCL tear especially in suspected cases.

Type of the study:Cross- sectional study.

Methods: Fifty patients are collected from casualty \& outpatient units from November/2014 to October/2016 with MCL injury in AL-Kindy teaching hospital.We decided to evaluate them under general anesthesia by valgus stress test at 30 degrees \& 0 degrees to estimate the integrity of $\mathrm{MCL}$, in addition to anterior \&posterior Drawer test to evaluate anterior \&posterior cruciate ligaments
\end{abstract}

Results: : From the 50 patients we select, there were 21 patients seen in the examination to have MCL tear.1 of them were Grade I ( $4.8 \%$ ), 14 of them were Grade II $(66.7 \%$ ),\&6 of them were Grade III (28.5\%)Associated injuries with ACL injury were 5 patients, with PCL injury were 1 patient and with medial capsular injury were 2 patients. Follow up of case range from (2-10) weeks with an average of 6 weeks combined with physiotherapy programs.

Conclusions: Diagnosis of MCL tear by valgus stress test under GA is the best method for the assessment of $\mathrm{MCL}$ tear in suspected cases.

Keywords: : MCL. valgus stress test .

\section{Al-Kindy College Medical Journal 2018: Vol. 14 No.1 Page: $37-41$}

\author{
*Specialist orthopedic surgeon in Al-Kindy teaching \\ hospital
}

Received $8^{\text {th }}$ June 2017, accepted in final $12^{\text {th }}$ Nov 2017

Corresponding to : Laith Saleem Sabri
$\mathrm{T}$ knee is the largest joint in the body and its security depends not so much on the intrinsic shape of its articular surfaces, but on the capsule and the powerful ligaments which bind the bones together, and on the muscles and tendons which surround it.It is nevertheless, a relatively unstable joint, which explains the frequency of injuries. ${ }^{(1,2,3)}$ The medial ligament consists of three portions; superficial, deep and oblique. ${ }^{(4)}$ Superficial part provides primary restraint to valgus stress at knee depending on knee flexion angle;deepfirmly attaches to the meniscus but does not provide significant resistance to valgus force ${ }^{(5)}$. Injuries to the $\mathrm{MCL}$ are usually caused by contact on the outside of the knee and are accompanied by sharp pain on the inside of the knee. Contrary to most other knee ligaments the medial collateral ligament (MCL) has an excellent ability to heal, being fairly large and well vascularised structure. The vast majority of isolated medial ligament injuries heal without significant long-term problems ${ }^{(5)}$. Injury to the MCL often occurs after an impact to the outside of the knee when the knee is slightly bent. The ligaments on the inside of the knee get stretched and can sometimes tear.The medial ligament has two parts to it. A deep part that attaches to the cartilage meniscus and a superficial part that attaches further down the joint. The deep part will rupture first and this often means that the cartilage is also damaged ${ }^{(6)}$. Many Classification for MCL injury like American Medical Association Committee on the Medical Aspects of Sports (7,8). And O'Donoghue classification; ${ }^{(9,10)}$ American Medical Association
Committee on the medical aspects of sports has three grades:

A. Grade 1 Injury: Minimal tear with no joint laxity. Angle opening on stress: 0 to $5 \mathrm{~mm}$.

B. Grade 2 Injury: Moderate tear with joint laxity. Angle opening on stress: 6 to $10 \mathrm{~mm}$

C. Grade 3 Injury: Complete tear with no firm endpoint. Angle opening on stress: 11 to $15 \mathrm{~mm}$

O'Donoghue classification also has three grades:

Grade 1 - Few torn fibers, structurally intact

Grade 2 - Incomplete tear, no pathologic laxity

Grade 3 - Complete tear, pathologic laxity

In our study we depend on American Medical Association Committee on the medical aspects of sports. A complete physical examination of the knee should be performed after a thorough history is obtained. Attention should be directed toward localizing the MCL injury and identifying any associated injuries. Inspection and palpation of the knee should identify the presence and location of point tenderness, localized soft tissue swelling, deformity, or ecchymosis. The region of injury within the ligament should be noted. A large joint effusion indicates an associated intra-articular injury. Outcome can be influenced by the location of the injury within the ligament. ${ }^{(11)}$ The integrity of the MCL is tested with a valgus stress. If any abnormal laxity is noted, the quality of the endpoint should be determined. Testing should be performed in full extension and at $30^{\circ}$ of flexion. Grading of the injury is based on the amount of 
laxity. Any laxity is compared to the opposite knee. ${ }^{(12)}$ Rotation should be compared to the opposite knee when evaluating for associated posteriomedialinjuries. Anterior and posterior draw signs and Apley's Grinding test are performed to rule out associated injuries. ${ }^{(12)}$ Other structures within the knee may be injured in association with the MCL. The anterior cruciate ligament (ACL), the medial meniscus,. the extensor mechanism, including the vastus medialis obliquus and retinacular fibers, the PCL may be injured. ${ }^{(12)}$ Joint aspiration: If a significant joint effusion is present, evaluation may be difficult. Using aseptic technique, the knee may be aspirated to allow for a more complete evaluation. A local anesthetic can be injected if the knee is too painful for evaluation. ${ }^{(13)} \mathrm{Knee}$ X-ray indicated in all suspected tears including anteroposterior , posteroanterior and lateral. Radiography should be performed to rule out fractures of the tibial plateau, patella, or distal femur.The PellegriniStieda lesion is indicative of an old injury and appears as a calcification at the femoral insertion of the MCL..The lateral capsular Segond fracture, suggests an associated ACL tear. This is a chip of bone still attached to the capsule after the capsule is avulsed from the lateral tibia. ${ }^{(14)} \mathrm{MRI}$ is important for diagnosis of MCL injury, the intact MCL is best demonstrated on T1- or T2-weighted coronal images. Partial tears or strains of MCL are seen with increased distance between the subcutaneous tissue and cortical bone.Mild increases in signal intensity on T2-weighted images without change in morphology correlate with a grade 1 tear increasing ligamentous size and signal intensity with attenuation correlate with grade $2 \mathrm{MCL}$ tear, Complete disruption of $\mathrm{MCL}$ on MRI correlate with grade 3 disruption.T2 or gradient echo fast scan images demonstrate; edema, hemorrhage, or both adjacent to low-signal-intensity fibers. $^{(15,16)}$ (Figure 1).

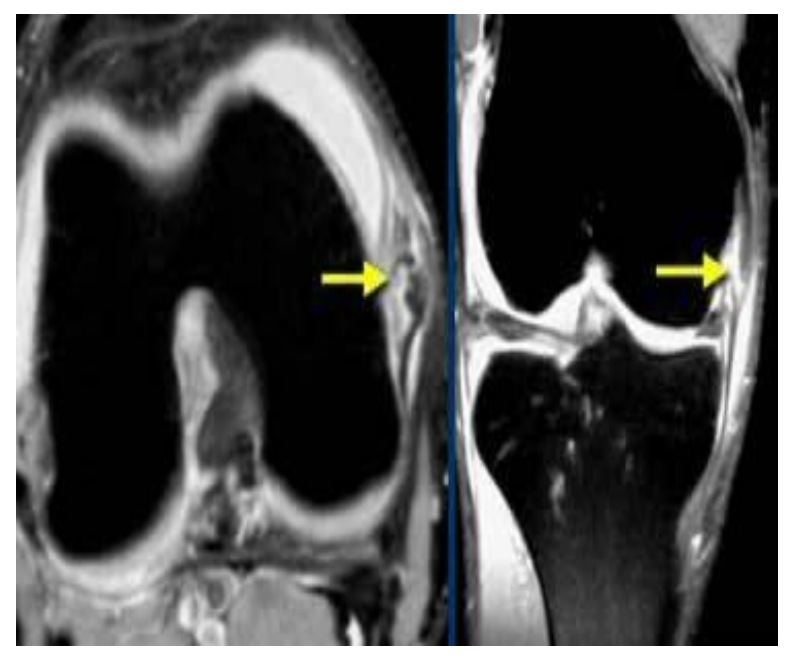

Figure 1: MRI of MCL tear.

Aim of the study is to compare between the early clinicalexamination, and assessment under GA, regarding the results and to find out which the two methods is the best to assess the MCL tear especially in suspected cases.

Methods: During the period between November 2014 and October 2016 a (50). patients with injury to the knee and suspicion of MCL injury were selectedat Al Kindy teaching hospital, from the casualty and outpatient units. The diagnosis based on taking history and clinical examination.During regional examination, we concentrate on making Valgus stress test without inducing much pain during the examination.Generally we select our group of patients basing on suspicion of having MCL injury. The suspicion made on specific criteria which include;

1- Mechanism of injury (sever Valgus force on the lateral side of the knee).

2- Sever pain, swelling and tenderness in medial aspect of the knee.

3- Apprehension and guardening of the patient from making the exam.

\section{4- Negative primary plain x-ray findings.}

We decide to examine our group of suspected patients under general anesthesia (GA), to exclude or confirm the presence of MCL tear.We admitted patients to the orthopedic ward, prepare them and complete investigations done, and assessment for fitness to anesthesia. Then they were admitted to the theater for fluoroscopic diagnosis under GA either in the same day, or in the day later. The goal of doing Valgus stress test and the Drawer test under GA was to estimate the degree of MCL tear, and other associated structures injuries, where the patient is anesthetized and there is no pain or guardening impending our exam. All the examinations were performed by our hand. The follow up of cases, range from 2-10 weeks with a mean of 4 weeks in the outpatient unit. In the early clinical assessment of the 50 patients we had; sex distribution was with male predominance, 46 patients were male and 4 patients were female, , forming $92 \%$ and $8 \%$ subsequently, the patients age range between 16-40 years with a mean age of (28) year.Right knee (32) cases, left knee (18) cases.Arthrocentesis was done for (22) patients (44\%).Medial side tenderness of the affected knee was positive in all the 50 patients, , and the tests applied to them were; Valgus stress test at 0 degree and 30 degree of knee flexion for assessment of MCL injury, anterior and posterior Drawer test and Apley $\mathrm{s}$ grinding test done for associated injuries. Fig 2 and 3. Hospitalization was based on the concept of day care procedure, putting the patient on discharge on oral non steroidal anti inflammatory drugs .We discharge the patients on an above knee splint in 30 degree flexion, to be reexamined after one week to assess the knee in the outpatient, and then putting above knee splint, and given another date to come to the outpatient unit. The duration of splint depend on the patient and the grade of $\mathrm{MCL}$ tear, and it was ranged from 2-6 weeks, during this time no weight bearing is allowed. After the removal of splint, we send the patient for physiotherapy, which includes gradual increase in the range of movement of the 
affected knee and quadriceps muscle strengthening exercises.

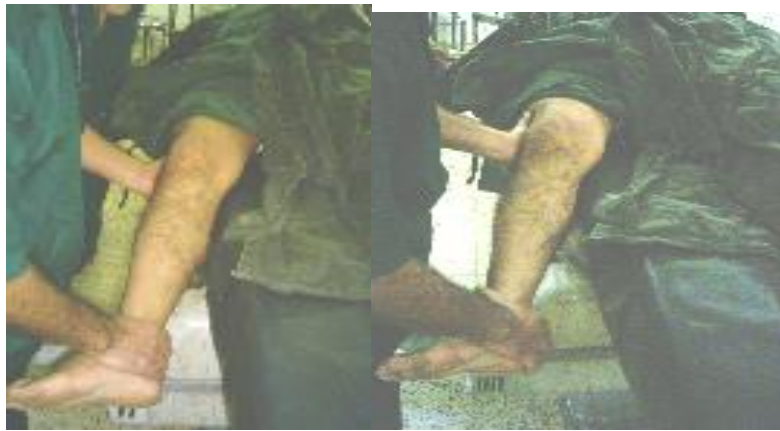

Figure 2: Valgus stress test at 0 and 30 degrees under GA.

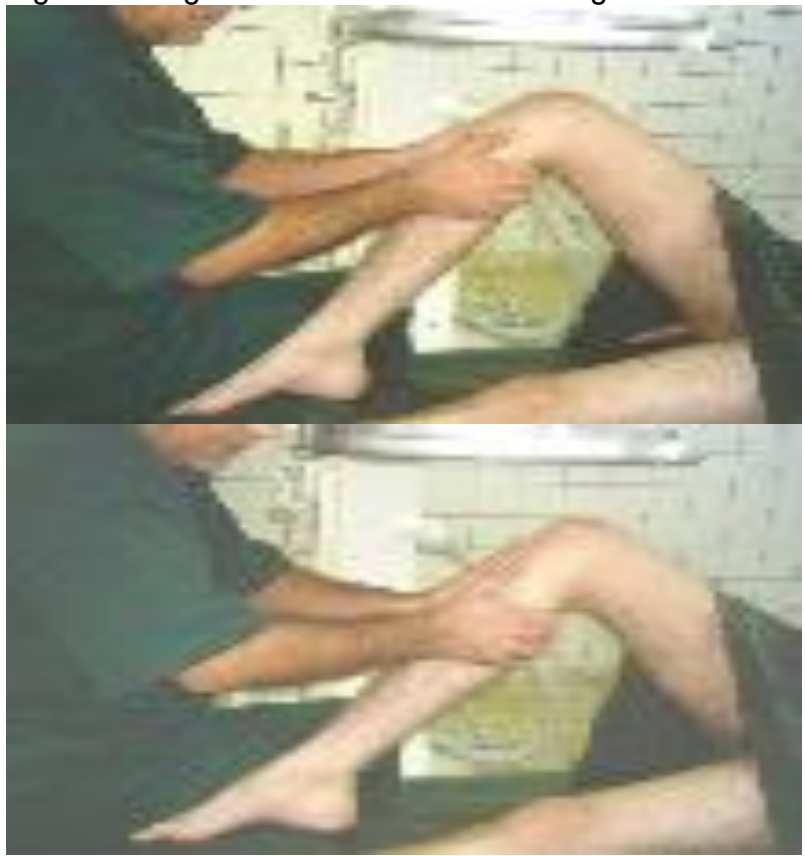

Figure 3: Anterior and posterior Drawer test under GA.

Results: All the data collected from the patients are based on the examination under GA.From the (50) patients admitted, (21) patients diagnosed to have MCL tear

Grades of MCL tear:Three of our 21diagnosed patients had a Grade I (14.3\%). 14 of the patients had a Grade II (66.7\%), \&4 of the patients had a Grade III (19.1\%) . Tab 1 and Graph 1. Grades of MCL Tear(Table (1)

\begin{tabular}{|c|c|c|}
\hline Grade of MCL tear & patients & percent \\
\hline Grade I & 1 & $4.8 \%$ \\
\hline Grade II & 14 & $66.7 \%$ \\
\hline Grade III & 6 & $28.5 \%$ \\
\hline
\end{tabular}

Associated injuries: By assessment under anesthesia we found that 13 patients had isolated tear of the MCL. $(61.9 \%)$, the remaining 8 patients had MCLtear associated with other knee structures injuries as shown in table2:

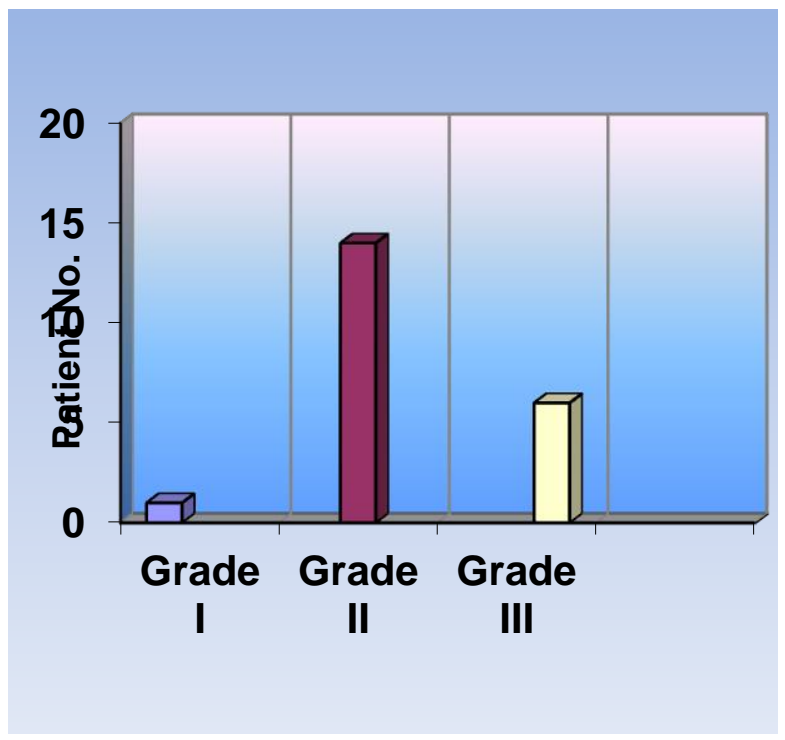

Graph (1): Grades of MCL Tear)

Table (2): Associated Injuries of MCL Tear

\begin{tabular}{|c|c|c|c|}
\hline No. & Type of Injury & $\begin{array}{l}\text { Patients } \\
\text { No. }\end{array}$ & percentage \\
\hline $\begin{array}{l}1 . \\
2 .\end{array}$ & $\begin{array}{l}\text { MCL + ACL } \\
\text { tear } \\
\text { MCL + PCL } \\
\text { tear } \\
\text { MCL+posterio- } \\
\text { medial } \\
\text { capsule tear }\end{array}$ & $\begin{array}{l}5 \\
1 \\
2\end{array}$ & $\begin{array}{c}23.8 \% \\
4.8 \% \\
9.5 \%\end{array}$ \\
\hline & Total & 8 & $38.1 \%$ \\
\hline
\end{tabular}

We collect the following data from the case report of the (21) patients with MCLtear, to find out what are the most probable causes, signs and symptoms of MCL tear.The most common cause of MCL tear in the (21) patients was athletic activities, especially in football players,we have 15 patients with MCLtear during sports i.e. (71.4\%) of the total number 21 as shown here in table 3 .

Table (3): Causes of MCL tear

\begin{tabular}{|l|l|l|}
\hline Cause of MCL tear & Patients & percentage \\
\hline Football or other sport & 15 & $71.4 \%$ \\
\hline Accidents & 5 & $23.8 \%$ \\
\hline Military & 1 & $4.8 \%$ \\
\hline Total & 21 & $100 \%$ \\
\hline
\end{tabular}


Of those 21 patients, who have the MCLtear confirmed by assessment under GA, all of them (100\%) were complained of pain at the medial side of the knee joint at the time of injury, 15 patientscouldn't walk directly after the injury $(71.4 \%), 6$ patients $(28.6 \%)$ couldn't continue the activity. see \{table 4 \}below:

Table (4): Symptoms of MCL Tear.

\begin{tabular}{|l|l|l|}
\hline Symptoms & No & percent \\
\hline Pain: & & \\
\hline Moderate (interferes with function) & 7 & 33.3 \\
Severe (:present most of the time) & 14 & 66.7 \\
Couldn't walk after injury & 15 & 71.4 \\
\hline Couldn't continue the activity & 6 & 28.6 \\
\hline
\end{tabular}

The commonest signs that could be found in patients with MCLtear were tenderness especially on the medial side of the joint (in 21 patients, i.e. 100\%). Ecchymosis in (11) patient $(52.4 \%)$ and in (14) patients had knee swelling due to joint effusion (66.7 \%) (Table 5).

Table-5-Signs of MCL Tear :

\begin{tabular}{|l|c|c|}
\hline Commonest signs & $\begin{array}{l}\text { Patients } \\
\text { No. }\end{array}$ & percentage \\
\hline $\begin{array}{l}\text { Tenderness on the } \\
\text { medial side of the } \\
\text { knee }\end{array}$ & 21 & $100 \%$ \\
\hline $\begin{array}{l}\text { Knee swelling due to } \\
\text { effusion: }\end{array}$ & 5 & $23.8 \%$ \\
Moderate & 7 & $33.3 \%$ \\
Severe & 11 & $52.4 \%$ \\
\hline Ecchymosis & & \\
\hline
\end{tabular}

Discussion: Though the tear of MCL is common among the knee ligaments injuries, it is some times indiagnosed because of underestimation during early examination.In our study we tried to make a definite diagnosis of MCL tear in all suspicious cases to overcome the problem of underestimation during primary exam of the patient after injury by the use of technique of examination under G.A.

Generally the aim from doing Valgus stress test under G.A was to:

1-Diagnose cases of $\mathrm{MCL}$ tear \&other associated injuries.

2-To arrangethe best management for the cases according to the findings.
All the procedures were performed to acutely injured patient who gets more benefit from our early diagnosis.To decrease the percent of false positive cases, we always examine the unaffected side firstly in order to compare with affected side \& by this we can avoid mistakes, such as in congenital laxity of ligaments.In the early clinical assessment we found that (50) patients had suspicion of MCL tear with or without associated other structures of the knee joint, while in the assessment under GA we found that only (21) patients had true MCL tear either isolated, or in association with other injuries like; $A C L, P C L$ or injury to the knee capsule.Also we get accurate assessment of the grade of MCL tear in the assessment under GA, while in the early clinical assessment of those (50) suspected patients we couldn't assess the grade of $\mathrm{MCL}$ tear accurately,so the assessment of MCL tear under GA is the best method, especially in suspected cases.In our study we found that MCL injury in suspicious cases of knee injuries after the assessment under GA are 21 of 50 cases $(42 \%)$, which is approximately similar to the other study $45 \%$ of suspicious cases 66 cases found to have MCL tear). ${ }^{(17)}$ On contrary to the search by Adam B Agranoff who found in his study (on96 case) that male \& female are equally affected, in our study we found that there is male predominance, male to female ratio was $90 \%-10 \%$ which is so different ${ }^{(18)}$ According to our study the prevalence rate was maximumbetween 20-29 years since we get $57.14 \%$ of occurrence in this group, which is approximately similar to that reported by Adam B Agranoff which also found that in peak incidence of MCL tear rate at age between $20-34$ years ${ }^{(18)}$. Most commonly encountered associated injuries with MCL tear was ACL tear, posteriomedial capsule and PCL tear.Were similler to other study(19)The most common gradesof $\mathrm{MCL}$ tears wereGrade II (66.7\%) and this appropriate to the result of other study who found the most common grade of MCL tear were Grade I and II. ${ }^{(20)}$ Undiagnosed cases of MCL tear, especially those with associated other ligament Injury, may develop instability of the knee joint with different degrees of the decrease in the range of motion as seen in cases presented to us late\& was misdiagnosed \& mistreated, on contrary to our cases in which early diagnosis provide early accurate treatment \& as we think better results.

Conclusions: Diagnosis of acute MCL tear by valgus stress test under G.A is frequently performed procedure though it is not widely used in most of our hospitals. Negative primary x-ray findings, doesn't exclude the presence of ligament tear .It would appear that careful selection of the suspected patients would be worthy to get the maximal benefit from this procedure.The benefit of this procedure is most rewarding as seen in our study as it diagnoses many patients to have ligament tear though we suspect the diagnosis at the primary examination. This procedure is short, easy, inexpensive, and not invasive in nature with minimal hospitalization time.We are satisfied with 
our result which we get from our procedure \& we regard it as the procedure of choice for the diagnosis of acute MCL tear of the knee.

\section{Recommendation:}

1- valgus stress test $\&$ associated tests under G.A are the selected procedures to diagnose MCL tear with or without other structures injury.

2- Definite diagnosis \&management of such cases lead to decrease complications in our work in comparism with neglected cases.

3- Those cases, with different types \&grades of MCL tear, mayneeds surgery or follow-up \& physiotherapy for at least 10 weeks.

\section{References}

1- Duthie \& Bentley, Mercer's orthopedic surgery. Affections of the knee joint, ninth edition, pp: 1125.

2- Kapandji IA: The Physiology of the Joints. New York: Churchill Livingstone, 2: 1970.

3- Knee joint- Anatomy \& function. The center for orthopedics \& sports medicine.1211 Johnson Ferry RD.; Marietta,GA., 30068.

4- Gray's Anatomy, Descriptive \& surgical. 15th edition. 1994. pp:248-249.

5- Medial Collateral Ligament . Grood ES et al et al: J Bone Joint Surg 1981;63A:1257-1269.

6- Medial Ligament Sprain(C)opyright Sports Injury Clinic 2005.

7- Canale S.T., Campbell's operative orthopedics. Tenth edition 2003 volume 3;( pp; 2166, pp;2171, pp;2199, pp;2202)

8- Family Practice, Collateral Ligament Tear of Knee; Kakarlapudi (2001) West J Med 174:266-72.

9- Medial Collateral Knee Ligament Injury.Lundberg M, Messner K. Am J Sports Med. Jan-Feb 1997; 25(1):2-6. (Medline).
10- Reider B. Medial collateral ligament injuries in athletes. Sports Med.Feb 1996; 21(2):147-56. (Medline)

11- Young JL, Olsen NK, Press JM: Musculoskeletal disorders of the lower limbs. In: Braddom RL, Buschbacher RM, eds. Physical Medicine and Rehabilitation. 1st ed. Philadelphia, Pa: WB Saunders 1996: 783-812

12- Fanelli GC, Edson CJ, Orcutt DR, et al. Treatment of combined anterior cruciate-posterior cruciate ligament-medial-lateral side knee injuries. J Knee Surg. Jul 2005;18(3):240-8. [Medline).

13- Strayer RJ, Lang ES: Evidence-based emergency medicine/systematic review abstract. Does this patient have a torn meniscus or ligament of the knee?. Ann Emerg Med 2006 May; 47(5): 499501[Medline).

14- Halinen J, Lindahl J, Hirvensalo E, Santavirta S. Operative and Nonoperative Treatments of Medial Collateral Ligament Rupture Am J Sports Med. Feb 1 2006; [Medline).

15- Li DK,adams ME, McConkey JP; Magnetic resonance imaging of the ligaments and menisci of the knee; Radiol Clin North Am (1995) 24:209-227.(Medline)

16- Turner DA, Prodromos CC, Pitasnick JP et al., Acute injury of the ligaments of the knee: Magnetic resonance evaluation, Radiology: (1996) 154: 717 722.( Medline)

17- American Journal of Sports Medicine, Vol 13, Issue 1 5-10, Copyright (C) 1985 by American Orthopaedic Society for Sports Medicine

18- eMedicine.com.Medial Collateral and Lateral Collateral Ligament Injury December 21, 2006, Adam B Agranoff, MD

19- eMedicine.com.Medial Collateral Knee Ligament Injury;May 30, 2006.

20- Medial Collateral Knee Ligament Injury, American Journal of Sports Medicine, Vol 22, Issue 1 2-11 